\section{Inactivation of $p 53$ and Pten promotes invasive bladder cancer}

\author{
Anna M. Puzio-Kuter, ${ }^{1,2,3}$ Mireia \\ Castillo-Martin,,2,4 Carolyn W. Kinkade, ${ }^{1,2,3}$ \\ Xi Wang, 2,5,6 Tian Huai Shen, ${ }^{2,4}$ Tulio Matos, ${ }^{2,4}$ \\ Michael M. Shen, ${ }^{2,5,6}$ Carlos Cordon-Cardo, ${ }^{1,2,4,8}$ \\ and Cory Abate-Shen ${ }^{1,2,3,4,7}$
}

\begin{abstract}
${ }^{1}$ Department of Urology, Columbia University, College of Physicians and Surgeons, New York, New York 10032, USA; ${ }^{2}$ Herbert Irving Comprehensive Cancer Center, Columbia University, College of Physicians and Surgeons, New York, New York 10032, USA; ${ }^{3}$ Center for Advanced Biotechnology and Medicine, University of Medicine and Dentistry of New JerseyRobert Wood Johnson Medical School, Piscataway, New Jersey 08854, USA; ${ }^{4}$ Department of Pathology, Columbia University, College of Physicians and Surgeons, New York, New York 10032, USA; ${ }^{5}$ Department of Medicine, Columbia University, College of Physicians and Surgeons, New York, New York 10032, USA; ${ }^{6}$ Department of Genetics and Development, Columbia University, College of Physicians and Surgeons, New York, New York 10032, USA
\end{abstract}

Although bladder cancer represents a serious health problem worldwide, relevant mouse models for investigating disease progression or therapeutic targets have been lacking. We show that combined deletion of p53 and Pten in bladder epithelium leads to invasive cancer in a novel mouse model. Inactivation of p53 and PTEN promotes tumorigenesis in human bladder cells and is correlated with poor survival in human tumors. Furthermore, the synergistic effects of p53 and Pten deletion are mediated by deregulation of mammalian target of rapamycin (mTOR) signaling, consistent with the ability of rapamycin to block bladder tumorigenesis in preclinical studies. Our integrated analyses of mouse and human bladder cancer provide a rationale for investigating $\mathrm{mTOR}$ inhibition for treatment of patients with invasive disease.

Supplemental material is available at http://www.genesdev.org.

Received December 15, 2008; revised version accepted January 30, 2009.

Bladder cancer is the fifth most common malignancy occurring worldwide and a major cause of cancer morbidity and mortality (Jemal et al. 2005). Approximately 90\% of bladder tumors are of epithelial origin, the majority corresponding to transitional cell carcinomas (Dinney et al. 2004; Eble et al. 2004; Reuter 2006). Early stage

[Keywords: Bladder cancer; mTOR signaling; mouse models; preclinical trials; rapamycin; tissue microarrays]

Corresponding authors.

${ }^{7}$ E-MAIL cabateshen@columbia.edu; FAX (212) 851-4572.

${ }^{8}$ E-MAIL cordon-c@columbia.edu; FAX (212) 851-4550.

Article published online ahead of print. Article and publication date are online at http://www.genesdev.org/cgi/doi/10.1101/gad.1772909. bladder tumors comprise two groups: low-grade, which are always papillary and usually superficial, and high-grade carcinoma in situ (CIS), which is the precursor of invasive bladder cancer. Superficial tumors, which account for the large majority $(\sim 75 \%-85 \%)$, typically have a favorable prognosis, while the 5 -yr survival for patients with invasive bladder cancer ( 25\% of all bladder tumors) can be less than $10 \%$ (Jemal et al. 2005). Notably, superficial and invasive bladder cancers are associated with distinct genotypic and phenotypic patterns (Wu 2005; CordonCardo 2008; Knowles 2008). In particular, chromosome 9 deletions and mutations of RAS and FGFR 3 occur in most, if not all, superficial papillary noninvasive tumors, but only in a small subset of invasive bladder tumors. In contrast, deletions of 3p, 5q, 10q (PTEN locus), 11p, 13q (RB locus), 17p (TP53 locus), and 18q (DCC locus) are absent or at least rare in superficial tumors, but occur frequently in invasive bladder carcinomas.

Until now, there has been a paucity of model systems that recapitulate invasive bladder cancer and thereby facilitate analyses of pathways of disease progression or identification and evaluation of targets for therapeutic intervention. Here, we describe a new mouse model of invasive bladder cancer that recapitulates many aspects of human bladder cancer. By integrating analyses from this new mouse model with correlative and functional data from human bladder cancer, we show that combinatorial inactivation of p53 and Pten are major causal factors that predict poor outcome of invasive bladder cancer. We further demonstrate that inactivation of $p 53$ and Pten leads to deregulation of the mammalian target of rapamycin (mTOR) signaling pathway, and, consequently, that inhibition of this signaling pathway blocks bladder tumor growth. Our findings provide a relevant preclinical model for therapeutic investigations, as well as a strong rationale for targeting the mTOR signaling pathway in patients with invasive bladder cancer.

\section{Results and Discussion}

\section{A new mouse model of invasive bladder cancer}

The bladder epithelium is comprised of several different cell types, including umbrella cells that line the bladder lumen, intermediate cells, and basal cells, which are adjacent to the lamina propria (Fig. 1A). Since the relationships of these cell types for bladder tumorigenesis has not yet been resolved, we utilized an approach for gene deletion that is not targeted to a particular cell type and/or differentiation status in the bladder epithelium. Specifically, we surgically delivered an adenovirus expressing Cre recombinase (hereafter referred to as AdenoCre) into the bladder lumen of adult male mice to induce conditional gene deletion in the epithelium (Fig. 1A). Using an $R 26 R$ reporter allele to evaluate targeting efficiency and specificity, we found that Adeno-Cre resulted in sporadic $(<10 \%)$ gene deletion exclusively in the epithelium and not in the underlying lamina propria or muscle layers $(n=10)$ (Fig. 1B,C).

We utilized this approach to evaluate the functional consequences of deleting tumor suppressor genes using the appropriate conditional alleles. Since inactivation of p53 leads to bladder tumors in transgenic mice (Zhang et al. 1999), and Pten deletion results in hyperplasia of 

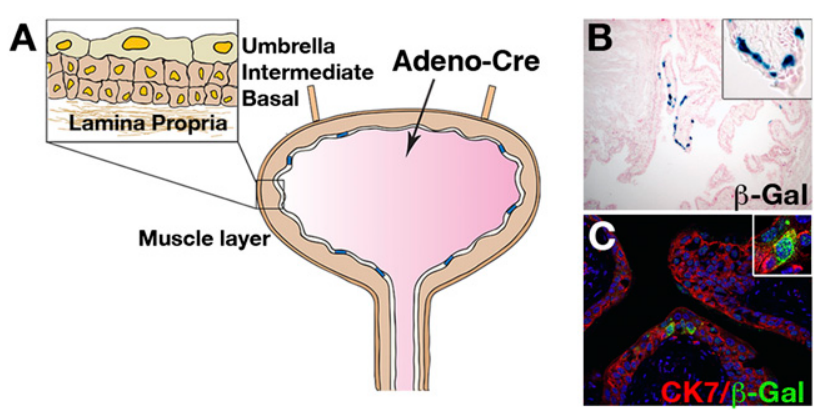

Figure 1. Targeted gene deletion in bladder epithelium via AdenoCre delivery. $(A)$ Schematic of bladder anatomy showing the layers of the epithelium. Adeno-Cre $\left(1 \mathrm{X} 10^{10} \mathrm{PFU}\right)$ was delivered into the bladder lumen of $R 26 R$ reporter mice and the location and extent of recombination was analyzed $3 \mathrm{~d}$ later by visualization of $\beta$-galactosidase staining $(B)$ or by immunofluorescence with colabeling by cytokeratin 7 to mark epithelial cells $(C)$.

bladder epithelium (Tsuruta et al. 2006; Yoo et al. 2006), we focused on their conditional inactivation alone or together. We observed bladder tumors only in mice having conditional alleles for both $p 53$ and Pten (p53 flox/flox; Pten $\left.{ }^{\text {flox/flox }}\right)$, which were strictly dependent on delivery of Adeno-Cre (Fig. 2A,B; Table 1; Supplemental Fig. 1). In particular, delivery of Adeno-Cre to the bladder lumen of p53 flox/flox Pten flox/flox mice produced large tumors (up to $2.4 \mathrm{~g}$ ) with $100 \%$ penetrance by 6 mo (Fig. 2A,B; Table 1 ). These bladder tumors displayed histological features of CIS, as well as high-grade invasive carcinoma with areas of transitional cell, squamous, and sarcomatoid carcinoma (Fig. 2C-H; Supplemental Fig. 2). Notably, the histological phenotype of the mouse tumors was highly reminiscent of CIS and high-grade invasive carcinoma in humans (Fig. 2I-N). Furthermore, these mouse bladder tumors were cytokeratin-positive, confirming their epithelial nature (Supplemental Fig. 3A,B), and those carrying the R26Rlac $Z$ reporter allele were strongly positive for $\beta$-galactosidase (Supplemental Fig. 1). These mice also displayed frequent visible metastases to local lymph nodes as well as to distant sites, including spleen, liver, and diaphragm (60\% occurrence by 4-6 mo), which were evident macroscopically and confirmed by immunohistochemical analyses (Table 1; Supplemental Fig. 3 E-G). Both p53 and Pten were efficiently recombined in the bladder tumors from Adeno-Cre-infected mutant mice (Supplemental Fig. 4). Notably, while loss of p53 was nearly complete, Pten was reduced but not eliminated (Supplemental Fig. 4). Immunohistochemical staining revealed residual Pten protein expression in endothelial cells, where it should not be eliminated by the targeting strategy, as well as in sporadic tumor cells, where, interestingly, it was predominantly nuclear (Supplemental Fig. 3C,D).

Notably, we failed to detect any bladder tumors in the p53 or Pten single mutants (p53 flox/flox Pten $^{+/+}$or $p 53^{+/+}$; $\left.P_{t e n}{ }^{\text {flox/flox }}\right)$ or various combinations of compound heterozygotes $\left(p 53^{\text {flox } /+} ;\right.$ Pten ${ }^{\text {flox } /+}$, p5 $53^{\text {flox } / \text { flox }}$; Pten ${ }^{\text {flox } /+}$, or $p 53^{\text {flox } /+}$; Pten ${ }^{\text {flox }}{ }^{\prime \prime l o x}$ ) for up to 1 yr following delivery of AdenoCre, while the histology of their bladder epithelium was within normal limits (Fig. 2A; Table 1; Supplemental Fig. 5). Furthermore, the p53; Pten compound mice contrast with mice harboring mutations of $R b$, which has been implicated in bladder tumorigenesis (Cordon-Cardo 2008; Knowles 2008), since deletion of $R b$ in bladder epithelium alone or in combination with either $p 53$ or Pten $\left(p 53^{\text {flox/flox }}\right.$; $R b^{\text {flox/flox }}$; or Pten ${ }^{\text {flox/flox }}$; $R b^{\text {flox/flox }}$ did not produce bladder tumors or result in grossly abnormal bladder histology (Table 1; Supplemental Fig. 6). We conclude that this Adeno-Cre delivery approach demonstrates a specific requirement for deletion of p53 and Pten for invasive bladder tumors in mice.

\section{Altered p53 and PTEN are associated with poor survival in human bladder cancer}

Next, we investigated the relevance of p53 and PTEN status in human invasive bladder cancer. While previous studies have reported frequent alterations of p53 in invasive bladder cancer that are associated with poor outcome (Esrig et al. 1994; Lianes et al. 1994; Sarkis et al. 1994) and have examined PTEN status (Cairns et al. 1998; Aveyard et al. 1999; Tsuruta et al. 2006), we are not aware of any that have investigated the association of PTEN inactivation with outcome or the coordinated alteration of p53 and PTEN in human bladder cancer. Therefore, we examined p53 and PTEN expression in tissue microarrays (TMAs) from two independent cohorts of human bladder tumors. The first had a total of 165 cases, including 135 cases of transitional cell carcinomas representative of all histological grades and stages, while the second included 85 cases from patients with muscle-invasive bladder cancer with extensive clinical follow-up data.

As expected, p53 was wild-type (undetectable) in noninvasive papillary tumors $(\mathrm{n}=23)$, while p53 alterations
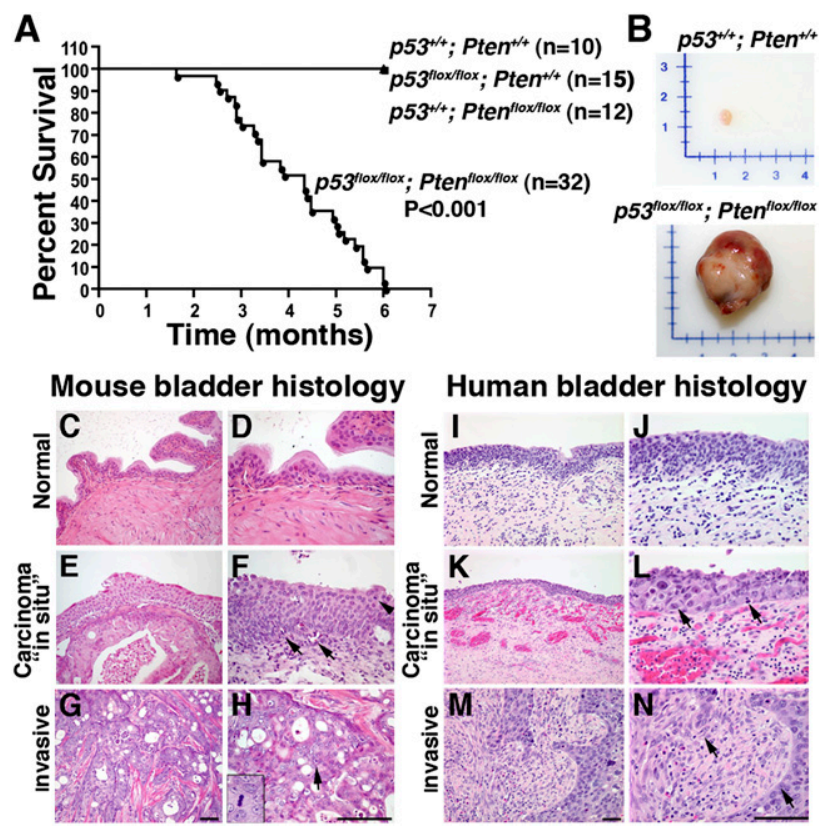

Figure 2. $p 53$ and Pten collaborate in suppression of invasive bladder cancer in mutant mice. $(A)$ Survival curve for mice of the indicated genotypes injected with Adeno-Cre and monitored for the length of time indicated. (B) Gross bladder phenotype following

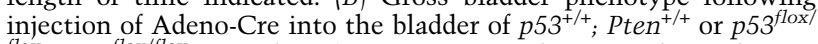
flox; Pten flox/flox mice. $(C-H)$ Representative hematoxylin and eosin

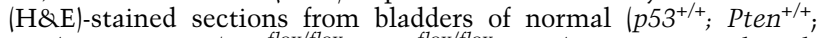
$C, D)$ or mutant (p53 flox/flox $;$ Pten flox/flox $; E-H)$ mice injected with Adeno-Cre. Arrows and inset in panels $F$ and $H$ show mitotic figures. $(I-N)$ H\&E-stained sections of human bladder, showing representative histology for comparison with the mouse bladder tumors. Bars, $100 \mu \mathrm{m}$. 


\begin{tabular}{|c|c|c|c|c|c|}
\hline Genotype' & $\begin{array}{l}\text { Mths post } \\
\text { adeno }\end{array}$ & $\mathrm{N}^{2}$ & $\begin{array}{l}\text { Bladder weight } \\
\text { (mgs) }\end{array}$ & Mets $^{3}$ & $\begin{array}{l}\text { Bladder } \\
\text { phenotype }\end{array}$ \\
\hline $\mathrm{p} 53^{+/ *} ; \mathrm{Pten}^{+/ t}$ & Up to 14 & 21 & $\begin{array}{l}\begin{array}{l}38.072 \pm 0.427 \\
(\mathrm{~N}=18)\end{array}\end{array}$ & None & Normal \\
\hline p53 $3^{\text {flox/lox }} ;$ Pten $^{+/ *}$ & Up to 14 & 29 & $\begin{array}{l}37.806 \pm 0.590 \\
(\mathrm{~N}=22)\end{array}$ & None & Normal \\
\hline p $53^{* / *} ;$ Pten $^{\text {nloxflox }}$ & Up to 14 & 31 & $\begin{array}{l}\text { 43.234 } 20.535 \\
(\mathrm{~N}=25)\end{array}$ & None & Normal \\
\hline $\mathrm{p} 53^{\ln 0 x /} ; \mathrm{Pten}^{\text {fox } / *}$ & Up to 8 & 9 & $\begin{array}{l}44.644 \pm 0.567 \\
(\mathrm{~N}=9)\end{array}$ & None & Normal \\
\hline 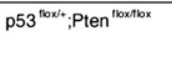 & Up to 8 & 9 & $\begin{array}{l}\begin{array}{l}70.843 \pm 5.698 \\
(N=7)\end{array}\end{array}$ & None & Normal \\
\hline $\mathrm{p} 53^{\operatorname{sox} / 10 x} ; \operatorname{Pten}^{\sin x / t}$ & Up to 8 & 7 & $\begin{array}{l}38.86 \pm 1.044 \\
(N=7)\end{array}$ & None & Normal \\
\hline \multirow{3}{*}{$\mathrm{p} 53^{\text {foxyllox }} ; \mathrm{Pten}^{\text {Hoxyllox }}$} & 0 to 2.5 & 15 & $\begin{array}{l}139.75 \pm 21.079 \\
(N=10)\end{array}$ & None & $\begin{array}{l}\text { Small tumors; In } \\
\text { situ CIS }\end{array}$ \\
\hline & 2.5 to 4.0 & 15 & $\begin{array}{l}1578.592 \pm 186.15 \\
(N=15)\end{array}$ & $\begin{array}{l}2 / 10 \\
(20 \%)\end{array}$ & $\begin{array}{l}\text { Large tumors; } \mathrm{CIS} \\
\text { and invasion }\end{array}$ \\
\hline & 4.0 to 6 & 14 & $\begin{array}{l}2403.43 \pm 236.517 \\
(N=10)\end{array}$ & $\begin{array}{l}6 / 10 \\
(60 \%)\end{array}$ & $\begin{array}{l}\text { Large tumors; CIS } \\
\text { and invasion; } \\
\text { Visible metastasis }\end{array}$ \\
\hline 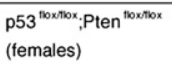 & Up to 6 & 5 & $\begin{array}{l}5274 \pm 1372.141 \\
\quad(\mathrm{~N}=4)\end{array}$ & $\begin{array}{l}3 / 4 \\
(75 \%)\end{array}$ & $\begin{array}{l}\text { Large tumors; CIS } \\
\text { and invasion }\end{array}$ \\
\hline $\mathrm{p} 53^{\text {noxithox }} ; \mathrm{Rb}^{\text {floxhlox }}$ & Up to 12 & 13 & $\begin{array}{l}28.634 \pm 1.001 \\
(\mathrm{~N}=13)\end{array}$ & None & Normal \\
\hline Pten $n^{10 x \pi 10 x} ; \mathrm{Rb}^{\text {thexhlox; }}$ & Up to 12 & 4 & $\begin{array}{l}33.400 \pm 2.037 \\
\quad(N=4)\end{array}$ & None & Normal \\
\hline \multicolumn{6}{|c|}{$\begin{array}{l}\text { 1. At least } 50 \% \text { of the mice in each group had the R26R reporter allele for verification of } \\
\text { targeting to bladder epithelium. }\end{array}$} \\
\hline \multicolumn{6}{|c|}{$\begin{array}{l}\text { 2. The total number }(\mathrm{N}) \text { in each group includes mice found dead and/or otherwise not subject } \\
\text { to complete phenotypic and histological analysis. }\end{array}$} \\
\hline \multicolumn{6}{|c|}{ 3. Refers to visible metastases (Mets) to lymph nodes, spleen, liver, and diaphragm. } \\
\hline
\end{tabular}

(p53 nuclear overexpression and/or TP53 gene mutations) were frequently observed in invasive bladder tumors $(n=$ 54) (Fig. 3A-D). Conversely, while PTEN was uniformly expressed in the epithelium of noninvasive papillary tumors (pTA, $n=23$ ), it was frequently down-regulated in invasive bladder tumors (thee out of 53 pT1-pT2, 17 out of 78 pT3-4 lesions; $P<0.05$ ) (Fig. 3E,F). Importantly, a high percentage of human bladder tumors with altered p53 also had deregulated expression of PTEN $(41 \%, n=$ 67) (see Fig. 3D,F).

Multivariate analyses revealed that altered expression of PTEN was associated with adverse patient outcome (Fig. 3G,H). In particular, Kaplan-Meier analyses based on PTEN immunoreactivity revealed a median survival of 3 yr for PTEN-positive cases compared with 9.5 mo for patients with PTEN-negative tumors $(P=0.005)$ (Fig. 3G). Moreover, patients with tumors classified as having alterations of both p53 and PTEN had a median survival of 6 mo versus those having p53 mutations but normal PTEN expression, who had a median survival 6 yr $(P<$ 0.001) (Fig. 3H). Therefore, combined alterations of p53 and PTEN occur frequently in invasive bladder cancer and are associated with poor patient outcome.

We next investigated potential causal roles of $p 53$ and PTEN for human bladder tumorigenesis using an in vivo cell recombination/renal grafting approach (Fig. 3I-P; Supplemental Fig. 7). We knocked down p53 and/or PTEN using four different combinations of two lentiviral-RNAi vectors for each gene in human bladder cells (Supplemental Table 1), followed by recombination of the cells with embryonic bladder mesenchyme and growth under the renal capsule of nude mouse hosts for up to 3 mo (Supplemental Fig. 7). We used the RT4 cell line, which was derived from a transitional cell papilloma (Rigby and Franks 1970) and is one of the few bladder epithelial cell lines that have both p53 and PTEN intact (Sanchez-Carbayo et al. 2002).

While the control RT4 cell recombinants formed lowgrade uroepithelial tumor lesions $(n=4)$, cell recombinants made with RT4 cells in which both p53 and PTEN had been knocked down displayed the typical morphology of a high-grade transitional cell carcinoma, including invasion into the surrounding mesenchyme and host kidney $(n=9)$ (Fig. 3J-P; Supplemental Table 1). In contrast, cell recombinants made with RT4 cells in which either p53 or PTEN alone was knocked down resembled the control RT4 cell recombinants ( $n=8$ per group) (Supplemental Fig. 7; Supplemental Table 1). Together with the correlative data in human bladder tumors and analyses of the mutant mice, these data demonstrate that p53 and PTEN functionally cooperate in suppression of bladder cancer and suggest that their combinatorial alteration in human bladder tumors defines a subgroup of patients with a particularly aggressive clinical course.

\section{Preclinical analyses of targeted pathways for invasive bladder cancer}

In other tissue contexts, cooperativity of Pten and $p 53$ has been shown to reflect their cross-talk on convergent signaling pathways, particularly involving mTOR signaling (Feng et al. 2005; Cully et al. 2006). We found that this pathway was also deregulated in mouse and human

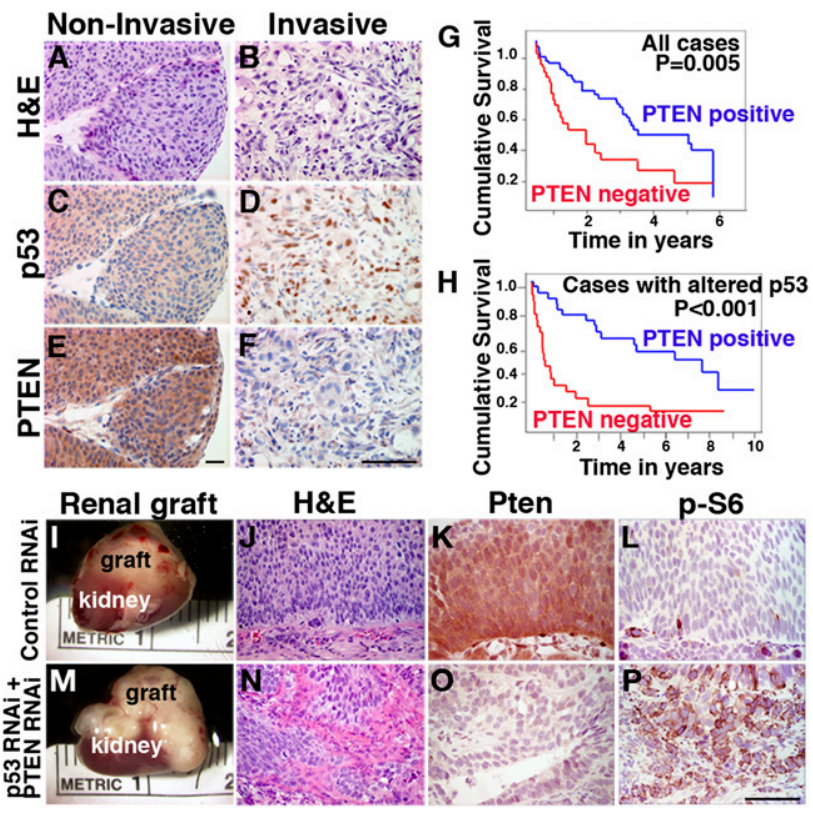

Figure 3. Altered $p 53$ and $P T E N$ are associated with poor survival in human bladder cancer. $(A-F)$ Tissue microarray analyses of p53 and PTEN showing immunohistochemical staining of human bladder tumors. $(G, H)$ Multivariate survival analyses. Kaplan-Meier plot for patients with clinical outcome data for Pten immunostaining in all patient samples $(G)$ and showing Pten-positive and Pten-negative tumors in patients harboring p53 mutations $(H)$. $(I-P)$ Functional analyses of p53 and PTEN inactivation in human bladder cells. Strategy: RT4 human bladder cancer cells were infected with lentiviral RNAi $(M O I=5)$ for p53 and/or PTEN, recombined with rat embryonic bladder mesenchyme, and grown under the renal capsule of a nude mouse for 3 mo. $(I, M)$ Gross morphology of the renal grafts. $(J, N)$ H\&E-stained sections. $(K, L, O, P)$ Immunostained sections. Bars, $100 \mu \mathrm{m}$. 

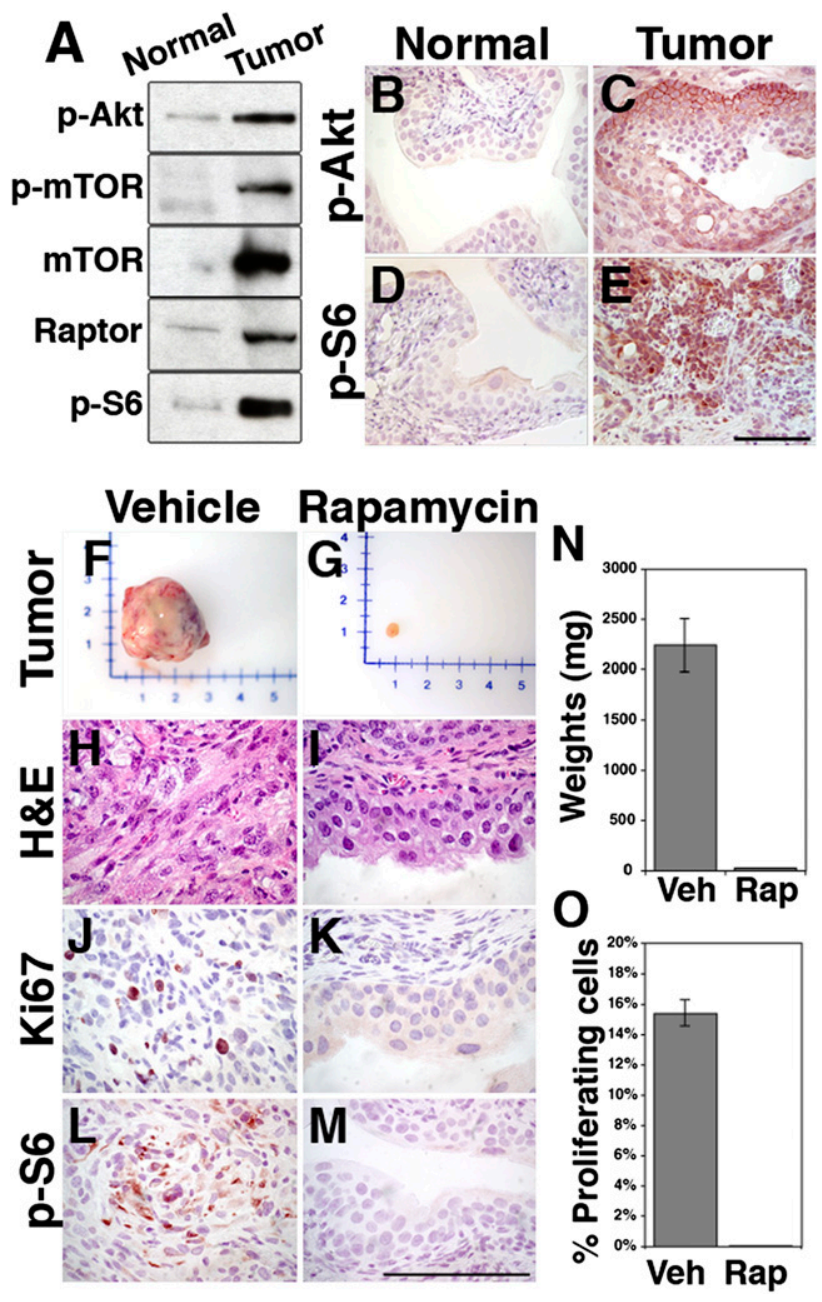

Figure 4. Preclinical analyses in the mutant mouse models. $(A-I)$ Activation of mTORCl in mouse and human bladder cancer. $(A)$ Western blot analyses showing the expression/activation of the indicated components of the mTORCl pathway in normal bladder $\left(\mathrm{p} 3^{+/+} ; \mathrm{Pten}^{+++}\right)$or bladder tumors $\left(\mathrm{p} 53^{\text {flox/flox }} ; \mathrm{Pten}^{\text {flox/flox }}\right)$ mice. Shown are representative data from analyses of five or more independent tumors. $(B-E)$ Immunostaining for activated p-Akt and p-S6 kinase in sections from control mice $\left(\mathrm{p53}^{+/+} ; \mathrm{Pten}^{+/+}\right)$or bladder tumors from $p 53^{\text {flox } / \text { flox }}$; Pten flox/flox $^{\text {mice. }}(F-O)$ Inhibition of mTORC1 inhibits bladder tumor growth in preclinical studies. One week following delivery of Adeno-Cre to the $p 53^{\text {flox/flox }}$; Ptenflox/flox mice, mice were randomly enrolled into the vehicle (Veh) and rapamycin (Rap) groups and delivered rapamycin (or vehicle) via daily i.p. injection for up to $5 \mathrm{mo} .(F, G)$ Gross morphology. $(H, I)$ H\&E-stained sections. (J-M) Immunostained sections. (N) Summary of bladder weights. (O) Summary of proliferation rates.

bladder tumors (Fig. 4A-E; Supplemental Fig. 8A-D). Thus, Akt was activated in mouse bladder tumors (Fig. $4 \mathrm{~A}-\mathrm{C})$, presumably as a consequence of Pten inactivation, as well as in a subset of human bladder tumors, where it was significantly correlated with tumor stage $(P<0.0001)$ (Supplemental Fig. 8A,B). Furthermore, the mouse and human bladder tumors displayed deregulation of several components of the mTORC1 complex (Guertin and Sabatini 2007; Manning and Cantley 2007). In particular, Western blot analyses of the mouse tumors revealed that mTOR, phospho-mTOR, Raptor, and phospho-S6 (p-S6) expression were strongly increased relative to normal bladder epithelium (Fig. 4A). The activation of mTOR signaling was further supported by immunohistochemical analyses, which revealed robust staining for p-S6 in the mouse tumors (Fig. 4D,E). Similarly, p70 S6 kinase (pS6K) was robustly activated in the subset of human bladder tumors displaying altered p53 and PTEN expression $(25 \%$ of invasive tumors), as well as in the cell recombination model (Fig. 3L,P; Supplemental Fig. 8C,D). Cumulatively, these findings show that the inactivation of p53 and Pten leads to deregulation of the mTOR signaling pathway in invasive bladder tumors.

To investigate the consequences of therapeutic targeting of the mTOR signaling pathway for bladder tumorigenesis, we performed preclinical studies in vivo using the mutant mouse model using both a prevention and treatment paradigm (Fig. 4F-O, Supplemental Fig. 8E-N). For the prevention paradigm, beginning $1 \mathrm{wk}$ following Adeno-Cre injection, we delivered vehicle or rapamycin (10 $\mathrm{mg} / \mathrm{kg}$ ), an inhibitor of mTORC1 (Bjornsti and Houghton 2004; Guertin and Sabatini 2007), for up to 5 mo and examined the consequences for bladder tumorigenesis. While the vehicle-treated mutant mice developed large bladder tumors as expected $(2241.55 \pm 257 \mathrm{mg})$, the bladders from the rapamycin-treated mice appeared grossly normal, having normal bladder weights $(28.7 \pm 0.782 \mathrm{mg})$ and no obvious histological abnormalities ( $n=5$ per group) (Fig. 4F-I,N). Furthermore, the bladder epithelium from rapamycin-treated mice displayed 16-fold reduced cellular proliferation relative to vehicle-treated counterparts $(P<$ 0.0001 ) and little or no expression of p-S6, a read-out of the mTOR signaling pathway (Fig. 4J-M,O). Therefore, rapamycin was highly effective for prevention of bladder tumor growth in the $p 53^{\text {flox/flox }} ;$ Pten ${ }^{\text {flox/flox }}$ mutant mice.

To complement these analyses, we investigated the consequences of rapamycin in a treatment paradigm, namely, the effect on growth of established tumors in a tissue recombination/renal grafting model. Specifically, cells from dissociated mouse bladder tumors were recombined with embryonic bladder mesenchymal cells, followed by growth for three months as renal grafts in vivo, during which time the tumor-bearing mice were treated daily with rapamycin or vehicle via i.p. injection (Supplemental Fig. 8E-N). The rapamycin-treated grafts displayed a significant reduction in tumor size $(28 \pm 5 \mathrm{mg}$; $n$ $=17)$ relative to vehicle-treated grafts $(151 \pm 16 \mathrm{mg} ; n=$ $20)$, coincident with a significant reduction in cellular proliferation $(P<0.0001)$ and reduced expression of $\mathrm{p}-\mathrm{S} 6$ (Supplemental Fig. 8E-N). Thus, these preclinical studies demonstrate the efficacy of rapamycin as an inhibitor of bladder tumor growth in vivo.

\section{Conclusions}

Mutations of p53 or PTEN are among the most frequent causal events in many cancers, and their combined inactivation has profound consequences for tumorigenesis in numerous contexts, including lymphoma, prostate cancer, glioblastoma, and medulloblastoma (Mao et al. 2003; Chen et al. 2005; Cully et al. 2006; Hambardzumyan et al. 2008; Kwon et al. 2008; Zheng et al. 2008). Our current findings establish the relevance of combinatorial inactivation of $p 53$ and PTEN for invasive bladder cancer and provide new insights regarding their context-dependent functions in tumor progression. Indeed, while a primary role for p53 in invasive bladder cancer has been well established (Cordon-Cardo 2008; 
Knowles 2008), our findings in mouse and human bladder cancer establish that loss of function of PTEN in combination with altered $p 53$ has deleterious consequences for invasive bladder cancer and identify a subgroup of patients with particularly aggressive disease.

Furthermore, our study highlights the value of integrating analyses of a relevant mouse model with correlative and functional human tumor and cell line data for delineating pathways of tumorigenesis, identifying rational targets for therapeutic intervention, and evaluating the efficacy of such targets in preclinical studies. In particular, our new model of invasive bladder cancer complements existing models based on forced expression of an SV40 large T transgene in the bladder epithelium, whose phenotype is attributed to inactivation of p53 (Zhang et al. 1999), or on inactivation of Pten throughout the bladder epithelium, resulting in widespread hyperplasia (Tsuruta et al. 2006; Yoo et al. 2006). Notably, the phenotypic differences between these previous models and the one described herein reveal the relevance of combined alteration of Pten and p53 for bladder tumorigenesis and underscore the stochastic rather than widespread gene deletion in bladder epithelium in our model.

Finally, our findings provide a strong rationale for therapeutic targeting of the mTOR signaling pathway in invasive bladder cancer, particularly in patients having deregulated p53 and PTEN, as well as a preclinical model for effective assessment of appropriate therapies. Notably, clinical successes with rapamycin analogs as single agents have been limited (Sawyers 2003; Guertin and Sabatini 2007), with some notable exceptions (Cloughesy et al. 2008; Le Tourneau et al. 2008). In contrast, rapamycin analogs have been shown to be more promising in combination with standard chemotherapy or agents that target other signaling pathways, particularly the RAS/MEK/MAP kinase pathway (Wang et al. 2006; Wendel et al. 2006; Fan et al. 2007; Legrier et al. 2007; Carracedo et al. 2008; Kinkade et al. 2008). Therefore, while rapamycin analogs represent a promising strategy in the treatment of invasive bladder cancer, it will also be important to investigate their efficacy in combination with other targeted therapies and/or chemotherapy (Shah and McKiernan 2004; Sonpavde et al. 2008; Wallerand et al. 2008). Notably, our study provides a relevant preclinical model for investigating targeted therapies for invasive bladder cancer, particularly those based on perturbation of mTOR signaling.

\section{Materials and methods}

Mouse alleles were obtained from the NCI Mouse models repository or the Jackson Laboratories. Adenovirus expressing Cre recombinase was obtained from University of Iowa's Vector Core Facility (http://www.uiowa.edu/ gene) and surgically delivered to the bladder lumen. At the time of sacrifice, tissues were collected and processed for histological, immunohistochemical, immunofluorescence, or Western blot analyses, as detailed in the Supplemental Material. Details of all antibodies are provided in the Supplemental Material.

Cell recombination assays were done by combining RT4 cells with rat embryonic mesenchyme and grown under the renal capsule of nude male mice. Tissue recombinants were made using normal bladder epithelium or tumors from mouse, recombined with rat embryonic mesenchyme and grown in culture or in the renal capsule of nude male mice. Knockdown studies were done with lentiviral RNAi from Sigma-Aldrich's Mission shRNA library (Sigma-Aldrich). Details of all lentiviral constructs are provided in the Supplemental Material. Rapamycin (from LC Laboratories) was provided once daily via i.p. at $10 \mathrm{mg} / \mathrm{kg}$ in vivo for up to $5 \mathrm{mo}$.

Human bladder cancer TMAs were made from a patient cohort of 165 tumors, with 136 transitional cell carcinomas and a second cohort of 86 muscle-invasive bladder cancers with clinical follow-up data. Scoring of the TMAs took into account the percentage of immunopositive tumor cells and intensity of staining. Statistical analyses were done using Mann-Whitney $U$-test, the $\chi^{2}$ test, or Fisher's exact test, and the Spearman correlation. Survival analysis was conducted by the log rank test and the Cox proportional hazard model.

\section{Acknowledgments}

This work was supported by grants UO1 CA084294 (C.A.-S.), CA1 15985 (M.M.S.), P30 CA13696 (C.C.-C.), NCI PO1 CA87497 (C.C.-C.), and NCI P50 CA91846 (C.C.-C.); the TJ Martell Foundation (C.A.-S. and C.C.-C.); and a Ruth L. Kirschstein National Research Service Award (CA1106625) to A.P.-K. M.M.S. and C.A.-S. are members of the NCI Mouse Models of Human Cancer Consortium.

\section{References}

Aveyard, J.S., Skilleter, A., Habuchi, T., and Knowles, M.A. 1999. Somatic mutation of PTEN in bladder carcinoma. Br. J. Cancer 80: 904-908.

Bjornsti, M.A. and Houghton, P.J. 2004. The TOR pathway: A target for cancer therapy. Nat. Rev. Cancer 4: 335-348.

Cairns, P., Evron, E., Okami, K., Halachmi, N., Esteller, M., Herman, J.G., Bose, S., Wang, S.I., Parsons, R., and Sidransky, D. 1998. Point mutation and homozygous deletion of PTEN/MMAC1 in primary bladder cancers. Oncogene 16: 3215-3218.

Carracedo, A., Ma, L., Teruya-Feldstein, J., Rojo, F., Salmena, L., Alimonti, A., Egia, A., Sasaki, A.T., Thomas, G., Kozma, S.C., et al. 2008. Inhibition of mTORC1 leads to MAPK pathway activation through a PI3K-dependent feedback loop in human cancer. J. Clin. Invest. 118: 3065-3074.

Chen, Z., Trotman, L.C., Shaffer, D., Lin, H.K., Dotan, Z.A., Niki, M., Koutcher, J.A., Scher, H.I., Ludwig, T., Gerald, W., et al. 2005. Crucial role of p53-dependent cellular senescence in suppression of Ptendeficient tumorigenesis. Nature 436: 725-730.

Cloughesy, T.F., Yoshimoto, K., Nghiemphu, P., Brown, K., Dang, J., Zhu, S., Hsueh, T., Chen, Y., Wang, W., Youngkin, D., et al. 2008. Antitumor activity of rapamycin in a Phase I trial for patients with recurrent PTEN-deficient glioblastoma. PLoS Med. 5: e8. doi: 10.1371/journal.pmed.0050008.

Cordon-Cardo, C. 2008. Molecular alterations associated with bladder cancer initiation and progression. Scand. J. Urol. Nephrol. 42: 154-165.

Cully, M., You, H., Levine, A.J., and Mak, T.W. 2006. Beyond PTEN mutations: The PI3K pathway as an integrator of multiple inputs during tumorigenesis. Nat. Rev. Cancer 6: 184-192.

Dinney, C.P., McConkey, D.J., Millikan, R.E., Wu, X., Bar-Eli, M., Adam, L., Kamat, A.M., Siefker-Radtke, A.O., Tuziak, T., Sabichi, A.L., et al. 2004. Focus on bladder cancer. Cancer Cell 6: 111-116.

Eble, J., Sauter, G., Epstein, J., and Sesterhenn, I. 2004. Tumors of the urinary system: Pathology and genetics. IARC Press, Lyon.

Esrig, D., Elmajian, D., Groshen, S., Freeman, J.A., Stein, J.P., Chen, S.C., Nichols, P.W., Skinner, D.G., Jones, P.A., and Cote, R.J. 1994. Accumulation of nuclear p53 and tumor progression in bladder cancer. N. Engl. J. Med. 331: 1259-1264.

Fan, Q.W., Cheng, C.K., Nicolaides, T.P., Hackett, C.S., Knight, Z.A., Shokat, K.M., and Weiss, W.A. 2007. A dual phosphoinositide3-kinase $\alpha / \mathrm{mTOR}$ inhibitor cooperates with blockade of epidermal growth factor receptor in PTEN-mutant glioma. Cancer Res. 67: 7960-7965.

Feng, Z., Zhang, H., Levine, A.J., and Jin, S. 2005. The coordinate regulation of the p53 and mTOR pathways in cells. Proc. Nat1. Acad. Sci. 102: 8204-8209. 


\section{Puzio-Kuter et al.}

Guertin, D.A. and Sabatini, D.M. 2007. Defining the role of mTOR in cancer. Cancer Cell 12: 9-22.

Hambardzumyan, D., Becher, O.J., Rosenblum, M.K., Pandolfi, P.P., Manova-Todorova, K., and Holland, E.C. 2008. PI3K pathway regulates survival of cancer stem cells residing in the perivascular niche following radiation in medulloblastoma in vivo. Genes \& Dev. 22: 436-448.

Jemal, A., Murray, T., Ward, E., Samuels, A., Tiwari, R.C., Ghafoor, A., Feuer, E.J., and Thun, M.J. 2005. Cancer statistics, 2005. CA Cancer J. Clin. 55: 10-30.

Kinkade, C.W., Castillo-Martin, M., Puzio-Kuter, A., Yan, J., Foster, T.H., Gao, H., Sun, Y., Ouyang, X., Gerald, W.L., Cordon-Cardo, C., et al. 2008. Targeting AKT/mTOR and ERK MAPK signaling inhibits hormone-refractory prostate cancer in a preclinical mouse model. $J$. Clin. Invest. 118: 3051-3064.

Knowles, M.A. 2008. Bladder cancer subtypes defined by genomic alterations. Scand. J. Urol. Nephrol. 42: 116-130.

Kwon, C.H., Zhao, D., Chen, J., Alcantara, S., Li, Y., Burns, D.K., Mason, R.P., Lee, E.Y., Wu, H., and Parada, L.F. 2008. Pten haploinsufficiency accelerates formation of high-grade astrocytomas. Cancer Res. 68: 3286-3294.

Legrier, M.E., Yang, C.P., Yan, H.G., Lopez-Barcons, L., Keller, S.M., Perez-Soler, R., Horwitz, S.B., and McDaid, H.M. 2007. Targeting protein translation in human non small cell lung cancer via combined MEK and mammalian target of rapamycin suppression. Cancer Res. 67: 11300-11308.

Le Tourneau, C., Faivre, S., Serova, M., and Raymond, E. 2008. mTORC1 inhibitors: Is temsirolimus in renal cancer telling us how they really work? Br. J. Cancer 99: 1197-1203.

Lianes, P., Orlow, I., Zhang, Z.F., Oliva, M.R., Sarkis, A.S., Reuter, V.E., and Cordon-Cardo, C. 1994. Altered patterns of MDM2 and TP53 expression in human bladder cancer. J. Natl. Cancer Inst. 86: 13251330 .

Manning, B.D. and Cantley, L.C. 2007. AKT/PKB signaling: Navigating downstream. Cell 129: 1261-1274.

Mao, J.H., Wu, D., Perez-Losada, J., Nagase, H., DelRosario, R., and Balmain, A. 2003. Genetic interactions between Pten and p53 in radiation-induced lymphoma development. Oncogene 22: 83798385.

Reuter, V.E. 2006. The pathology of bladder cancer. Urology 67: 11-17.

Rigby, C.C. and Franks, L.M. 1970. A human tissue culture cell line from a transitional cell tumour of the urinary bladder: Growth, chromosone pattern and ultrastructure. Br. J. Cancer 24: 746-754.

Sanchez-Carbayo, M., Socci, N.D., Charytonowicz, E., Lu, M., Prystowsky, M., Childs, G., and Cordon-Cardo, C. 2002. Molecular profiling of bladder cancer using cDNA microarrays: Defining histogenesis and biological phenotypes. Cancer Res. 62: 6973-6980.

Sarkis, A.S., Dalbagni, G., Cordon-Cardo, C., Melamed, J., Zhang, Z.F., Sheinfeld, J., Fair, W.R., Herr, H.W., and Reuter, V.E. 1994. Association of P53 nuclear overexpression and tumor progression in carcinoma in situ of the bladder. J. Urol. 152: 388-392.

Sawyers, C.L. 2003. Will mTOR inhibitors make it as cancer drugs? Cancer Cell 4: 343-348.

Shah, J.B. and McKiernan, J.M. 2004. Novel therapeutics in the treatment of bladder cancer. Curr. Opin. Urol. 14: 287-293.

Sonpavde, G., Ross, R., Powles, T., Sweeney, C.J., Hahn, N., Hutson, T.E. Galsky, M.D., Lerner, S.P., and Sternberg, C.N. 2008. Novel agents for muscle-invasive and advanced urothelial cancer. BJU Int. 101: $937-$ 943.

Tsuruta, H., Kishimoto, H., Sasaki, T., Horie, Y., Natsui, M., Shibata, Y., Hamada, K., Yajima, N., Kawahara, K., Sasaki, M., et al. 2006. Hyperplasia and carcinomas in Pten-deficient mice and reduced PTEN protein in human bladder cancer patients. Cancer Res. 66: 8389-8396.

Wallerand, H., Reiter, R.R., and Ravaud, A. 2008. Molecular targeting in the treatment of either advanced or metastatic bladder cancer or both according to the signalling pathways. Curr. Opin. Urol. 18: 524-532.

Wang, M.Y., Lu, K.V., Zhu, S., Dia, E.Q., Vivanco, I., Shackleford, G.M. Cavenee, W.K., Mellinghoff, I.K., Cloughesy, T.F., Sawyers, C.L., et al. 2006. Mammalian target of rapamycin inhibition promotes response to epidermal growth factor receptor kinase inhibitors in PTENdeficient and PTEN-intact glioblastoma cells. Cancer Res. 66: 7864-7869.
Wendel, H.G., Malina, A., Zhao, Z., Zender, L., Kogan, S.C., CordonCardo, C., Pelletier, J., and Lowe, S.W. 2006. Determinants of sensitivity and resistance to rapamycin-chemotherapy drug combinations in vivo. Cancer Res. 66: 7639-7646.

Wu, X.R. 2005. Urothelial tumorigenesis: A tale of divergent pathways. Nat. Rev. Cancer 5: 713-725.

Yoo, L.I., Liu, D.W., Le Vu, S., Bronson, R.T., Wu, H., and Yuan, J. 2006. Pten deficiency activates distinct downstream signaling pathways in a tissue-specific manner. Cancer Res. 66: 1929-1939.

Zhang, Z.T., Pak, J., Shapiro, E., Sun, T.T., and Wu, X.R. 1999. Urothelium-specific expression of an oncogene in transgenic mice induced the formation of carcinoma in situ and invasive transitional cell carcinoma. Cancer Res. 59: 3512-3517.

Zheng, H., Ying, H., Yan, H., Kimmelman, A.C., Hiller, D.J., Chen, A.J., Perry, S.R., Tonon, G., Chu, G.C., Ding, Z., et al. 2008. p53 and Pten control neural and glioma stem/progenitor cell renewal and differentiation. Nature 455: 1129-1133. 


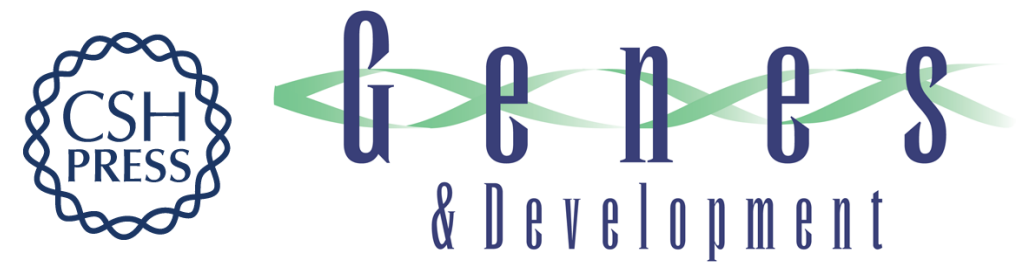

\section{Inactivation of $p 53$ and Pten promotes invasive bladder cancer}

Anna M. Puzio-Kuter, Mireia Castillo-Martin, Carolyn W. Kinkade, et al.

Genes Dev. 2009, 23: originally published online March 4, 2009

Access the most recent version at doi:10.1101/gad.1772909

\footnotetext{
Supplemental http://genesdev.cshlp.org/content/suppl/2009/03/12/gad.1772909.DC1

Material

Related Content Bladder cancer: modeling and translation

Jonathan E. Rosenberg and William C. Hahn

Genes Dev. March , 2009 23: 655-659

References This article cites 38 articles, 11 of which can be accessed free at: http://genesdev.cshlp.org/content/23/6/675.full.html\#ref-list-1

Articles cited in:

http://genesdev.cshlp.org/content/23/6/675.full.html\#related-urls

License

Email Alerting Receive free email alerts when new articles cite this article - sign up in the box at the top

Service right corner of the article or click here.
}

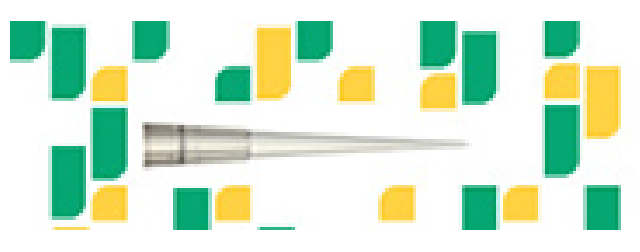

Focused on your science. 